\title{
Superior Mesenteric Artery occlusion presenting with severe acute abdomen and subsequent gangrenous small gut
}

\author{
Chishti Tanhar Bakth ${ }^{1}$, Jamal Ahmed ${ }^{2}$, Mrigen Kumar Das ${ }^{3}$
}

\begin{abstract}
Superior Mesenteric Artery occlusion is not very uncommon in developing world. It mimic clinically with many differential diagnosis. ${ }^{2}$ There is a clinical scenario of 60 yrs male, smoker presented in Accident \& Emergency $(A \& E)$ department with history of central abdominal pain for two days associated with vomiting. Pain was gradually increasing, abdomen became tense, tender and patient developed restlessness. Even after all sorts of conservative management, pain was not subsiding. Following day of admission laparotomy attempted with clinical vision of burst appendix and peritonitis. After exploration of abdomen the finding was thundering. The almost whole small gut was gangrenous, resection anastomosis had done. In this case the differential diagnosis was burst appendix and Intestinal obstruction. Possibility of Superior Mesenteric Artery occlusion should be kept in mind by this clinical ground.
\end{abstract}

Keywords: Superior Mesenteric Artery, Laparotomy, Gangrene.

\section{Introduction:}

Acute superior mesenteric artery occlusion which can result in an acute mesenteric ischaemia and can be a life threatening event related to the artery supplying the majority of small bowel and right side of colon ${ }^{1}$. An acute occlusion is an uncommon event that typically affects elderly patients who are at increased risk of other cardiovascular events. Because of the high rate of mortality and the difficulty of diagnosis, mesenteric ischaemia poses a substantial legal risk. This risk can be reduced by a high degree of clinical suspicion, early and aggressive diagnostic imaging and early surgical intervention with clear documentation of timing.

\section{Case presentation:}

A 60 years of male, smoker presented in A\&E department with history of central abdominal pain for two days and associated with vomiting. Emmergency Medical Officer (EMO) had evaluated the patient. He had no comorbid illness or surgical history.

On examination, hemodynamics were stable, abdomen examination revealed tenderness in central abdomen with

1. Dr. Chishti Tanhar Bakth Choudhury, MS (Surg), MCPS (Surg), Consultant surgeon, Sylhet Womens Medical college Hospital E-mail : chishtitanharbakthchoudhury@yahoo.com.

2. Dr. Jamal Ahmed Chowdhury, FCPS (Surg), Professor, Sylhet Womens Medical College Hospital,

E-mail : jamal_achowdhury@hotmail.com

3. Dr. Mrigen Kumar Das Chowdhury, FCPS (Surg), Professor, Sylhet Womens Medical College Hospital, E-mail : dr.mrigen.chowdhury@gmail.com

Corresponding Author:

Dr. Chishti Tanhar Bakth Choudhury

MS (Surg), MCPS (Surg), Consultant surgeon

Sylhet Womens Medical College Hospital

E-mail : chishtitanharbakthchoudhury@yahoo.com

Phone: +8801717026037 sluggish bowel sound. Pain intensity was increasing in timely fashion and abdomen became tense, tender with diminished bowel sound. Finally he developed severe agonizing pain for which he was unable to talk and breath normally. His pulse was $>120$ beat per minute and became very restless. His abdominal pain was not subsiding even with mixed analgesics.

Hematological investigations showed neutrophilic leukocytosis, urine routine examination revealed pus cell 6-10 per high power field (HPF), RBC 3-5/HPF, USG of whole abdomen showed fine floating echogenic debris in urinary bladder otherwise normal USG. Other relevant investigations (LFT, RFT, X-RAY, amylase, lipase, ECG) were normal.

Patient became very toxic with evidence of diffuse peritonitis, exploration of abdomen was planned and the findings were thundering. Almost the whole small gut was gangrenous (Figure), after resection of gangrenous gut, approximately 30 $\mathrm{cm}$ of gut could be saved. Tensionless jejuno-ileal anastomosis was made after examining for the evidence of gut viability. Total procedure took about 3 hours and 2 units of whole blood were transfused with infusion of about 3 liters of crystalloidal solution per-operatively. Patient was shifted to ICU in a orotracheally intubated state for close hemodynamic monitoring and ventilatory support. Though patient developed dys-electrolytaemia and acute lung injury on postoperative days but gradual improvment was there. on $8^{\text {th }}$ post-operative day liquid diet was started orally, but there was evidence of anastomotic leakage on two drain tube sites. Patient again developed peritonitis and subsequent septicaemia. But unfortunately patient died on $18^{\text {th }}$ post-operative day .

\section{Discussion:}

Acute Superior Mesenteric Artery occlusion is time dealing case $^{2}$. Early prediction of disease, the damage would be the minimum. In late age with atypical presentation of abdomen with atypical clues of lab findings, mesenteric occlusion 
should be kept in mind as a important differential diagnosis. Differential diagnosis comes from intense history taking, clinical and abdominal findings and laboratory support.

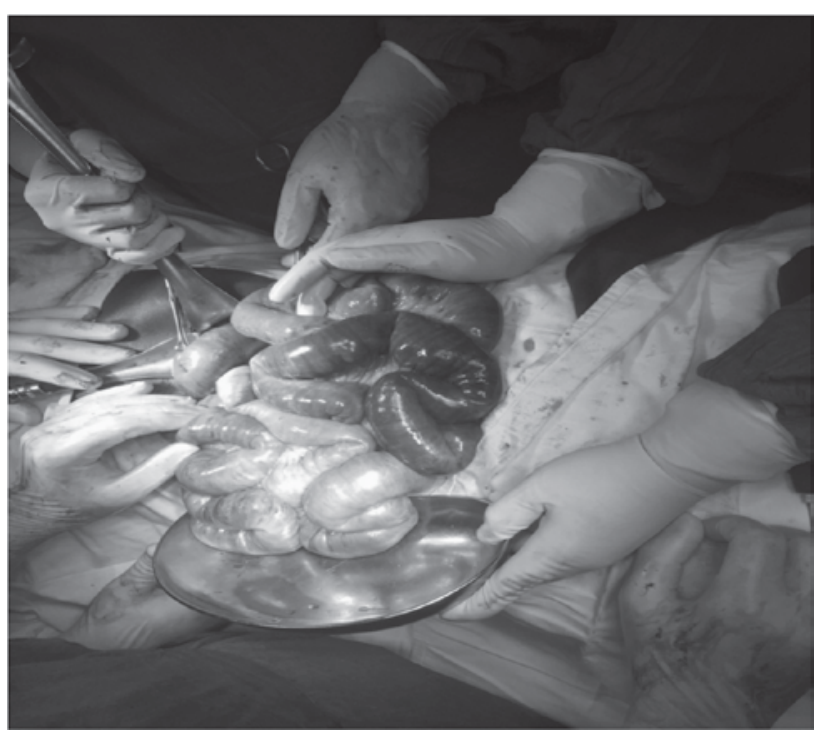

Fig : Per-opearative infarcted small gut

Mesenteric occlusion causes impairment of gut viability. Early exploration of abdomen and thrombectomy can minimize the damage of gut. CT or MR angiogram can diagnose the disease early as well as combined vascular and general surgeon should start the work. Mesenteric occlusion is a life threatening, more than $80 \%$ mortality even in all facilitated place.

\section{Conclusion:}

Clinicians need to have high suspicion of Acute Superior Mesenteric Artery occlusion in their dfferentials when dealing with such presentation in a elderly morbid patient.

\section{Learning Points}

a. Emergency exploration as early as possible can minimize damage. b. Both end of gut exteriorization can minimize the leakage rate although fluid and electrolytes management is challenging.

c. CT or MR angiogram needed to localize the thrombus and for resection.

d. It is a multidisciplinary approach involvement process and should need to involve multiple faculties including intensivist.

e. Intraluminal papaverine has contribution in occlusion.

f. Predisposing factors are old age ,smoking, prothrombotic tendency, vascular, cardiac cause ( mechanical heart valve, atrial fibrillation, acute MI).

\section{Consent:}

Verbal consent has been obtained from patient attendance to participate in this case report.

\section{References:}

1. Bradbury AW, et al. Br J Surg 1995; 82: 1446-59

2. Brandt LJ, Feuerstadt P. Intestinal ischaemia . In: Feldman M, Friedman LS, Brandt LJ, eds. Sleisenger and Fordtrans Gastrointestinal and liver disease . $10^{\text {th }}$ ed. Philadelphia, PA: Elsevier saunders; 2016: chapt 118.

3. Bergan j.j. : Recognition and treatment of intestinal ischaemia . surg. Clin.N . Amer. , 147: 109, 1967.

4. Hauser SC. Vascular disease of the gastrointestinal tract. IN: Goldman L, Schafer Al, eds. Goldmanscecil Medicine. $25^{\text {th }}$ ed. Philadelphia, PA: Elsevier Saunders; 2016 :chapt 143.

5. Jackson , B.B. : Occlusion of the superior mesenteric artery. springfield, Illinois, charles C Thomas, 1963, P. 40. 